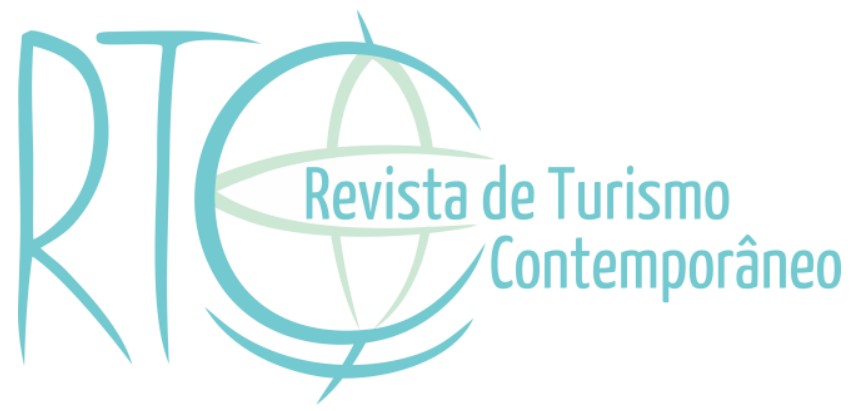

\title{
Uma análise do antigo Sistema Brasileiro de Classificação de Meios de Hospedagem a partir do Complexo Turístico do Porto das Dunas, Fortaleza/Brasil
}

\section{An analysis of the old Brazilian System of Classification of Accommodation Facilities from the Porto das Dunas Tourist Complex, Fortaleza/Brazil}

\section{Francisca Lúcia Sousa de Aguiar}

Professora Efetiva nos Cursos de Tecnologia em Hotelaria e Técnico em Hospedagem do Instituto Federal do Ceará - IFCE, Fortaleza/CE, Brasil

E-mail: luciafederal@gmail.com

\section{Adriana Santos Brito}

Professora Convidada da Pós-Graduação em nível de Especialização Latu Sensu em Docência do Ensino Superior do Instituto Dexter - Desenvolvimento Humano - Parnaíba/PI, Brasil E-mail: adryannabrito@hotmail.com

\section{André Riani Costa Perinotto}

Professor do curso de Bacharelado em Turismo da Universidade Federal do Delta do Parnaíba - UFDPar, Parnaíba/PI, Brasil

E-mail: perinotto@ufpi.edu.br 


\section{RESUMO}

Nesse trabalho propõem-se analisar os requisitos recomendados pelo Ministério do Turismo do Brasil (MTur) para a classificação da tipologia resort no Sistema Brasileiro de Classificação de Meios de Hospedagem (SBClass) nos três empreendimentos hoteleiros, auto classificados de resorts, que fazem parte do complexo turístico do Porto das Dunas em Fortaleza, Ceará, Brasil. Para tal, buscou-se verificar quais requisitos do SBClass são atendidos pelos resorts desse empreendimento, a partir da Matriz de Classificação do SBClass. Na metodologia utilizou-se a pesquisa documental e de campo, com abordagem qualitativa e método netnográfico. Os instrumentos de coleta de dados foram um (01) questionário contendo dez (10) questões, e a Matriz de Classificação - Tipologia Resort do MTur. A coleta de dados aconteceu a partir de 66 avaliações postadas na plataforma do TripAdvisor, entre março a maio de 2018. A análise dos dados foi realizada por meio do método netnográfico no qual obteve-se um percentual para o atendimento dos requisitos de: infraestrutura, serviços e sustentabilidade, respectivamente: $86 \%, 83 \%$ e $100 \%$ de itens obrigatórios presentes nos três resorts do complexo turístico do Porto das Dunas.

Palavras-chave: Sistema Brasileiro de Classificação de Meios de Hospedagem (SBClass). Requisitos do SBClass. Resorts. Netnografia.

\section{ABSTRACT}

This paper proposes to analyze the requirements recommended by the Brazilian Ministry of Tourism (MTur) for the classification of the resort typology in the Brazilian System of Classification of Means of Lodging (SBClass) in the three self-classified resort hotels, which are part of the Port of Dunas tourist complex in Fortaleza, Ceara, Brazil. To this end, we sought to verify which SBClass requirements are met by the resorts of this venture, from the SBClass Rating Matrix. The methodology used was documentary and field research, with qualitative approach and netnographic method. The data collection instruments were one (01) questionnaire containing ten (10) questions, and the MTur Classification Resort Matrix. Data collection took place from 66 evaluations posted on the TripAdvisor platform, from March to May 2018. Data analysis was performed using the netnographic method which obtained a percentage to meet the requirements of: infrastructure, services and sustainability, respectively: $86 \%, 83 \%$ and $100 \%$ of mandatory items present in the three resorts of Port of Dunas tourist complex.

Keywords: Brazilian System of Classification of Means of Lodging (SBClass). Requirements of SBClass. Resorts. Netnography. 


\section{INTRODUÇÃO}

O desenvolvimento da atividade turística é de grande relevância para toda e qualquer sociedade, tendo em vista que o turismo é uma atividade realizada por pessoas, a partir de viagens para lugares diferentes de onde residem, proporcionando uma vivência diferente das desenvolvidas na sua rotina diária e que lhes ofereça facilidades e atenda às suas necessidades no destino turístico (Mota, Vianna, \& Anjos, 2013).

Para o atendimento das distintas necessidades de um turista, dentre elas a de hospedagem, foi necessária a implantação e o desenvolvimento dos meios de hospedagem, vastamente diversificados e percebidos no histórico da hotelaria.

O progresso dos empreendimentos hoteleiros vem ocorrendo desde o início até a atualidade, em distintos aspectos. Ao longo da história, foram apresentando, a partir de suas características específicas, uma diversidade de tipologias, como pode ser constatado por Beni (2002), que divide os empreendimentos em hoteleiros e extra hoteleiros, listando um total de 21 tipologias. Já Campos e Gonsalves (2005) apresentam 22 tipologias, sendo que algumas já são diferentes das citadas pelo primeiro autor. Logo, essa diversidade passou a dificultar ao turista a busca pelo empreendimento ideal ao atendimento de suas necessidades.

Diante disso, o Ministério do Turismo - MTur, com o objetivo de possibilitar a concorrência justa entre os meios de hospedagem do país e auxiliar os turistas, brasileiros e estrangeiros, em suas escolhas, optou por uma classificação padronizada, coerente com as diversidades dos tipos de meios de hospedagem e baseada em critérios técnicos. Assim, lançou a Portaria $n^{\circ}$ 100, de 16 de junho de 2011, a qual instituiu o Sistema Brasileiro de Classificação de Meios Hospedagem (SBClass) como estratégia para promover e assegurar a competitividade em um mercado global altamente disputado (Ministério do Turismo, 2010).

É a partir desse histórico que surge a motivação para falar do tema estudado, tendo em vista que, desde 1977, os governos do Brasil buscam implantar um sistema de classificação de meios de hospedagem que seja eficiente e possua requisitos que atendam às necessidades dos empreendimentos hoteleiros, bem como dos hóspedes. O fato de estudar os requisitos presentes na Matriz de Classificação do último Sistema de Meios de Hospedagem implantado, em 2011, o SBClass, dentro de três resorts conceituados, por fazerem parte do Complexo Turístico conceituado do Porto das Dunas, torna-se uma oportunidade de verificar se os requisitos propostos na referida Matriz condizem com a realidade presente nos meios de hospedagem.

Pelo fato de ter sido selecionado dentre tantas tipologias existentes no mercado hoteleiro para fazer parte dos sete empreendimentos de classificação oficial do MTur, e apresentar como 
categoria o número máximo de estrelas, quatro ou cinco, o resort configura-se como um significativo meio de hospedagem para os cenários nacional e internacional.

A Associação Brasileira de Resorts - ABR (2017) define resorts como empreendimentos hoteleiros, construções de alto padrão nas instalações e serviços, voltados primordialmente para lazer e turismo. Esses foram crescendo consideravelmente em ocupação ao longo dos anos, como divulga o presidente da ABR, informando que as taxas de ocupação geral dos resorts brasileiros apresentaram crescimento no $1^{\circ}$ trimestre de 2017 de 68,3\%, a qual obteve aumento em relação a 2016.

Dentre eles, estão os empreendimentos hoteleiros, auto classificados de resorts pelo complexo turístico do Porto das Dunas, um complexo aquático localizado no litoral do Ceará, voltado para diversão, lazer e turismo, tendo como uma de suas melhores atrações o maior parque aquático da América Latina e o segundo maior do mundo.

Nesse contexto, surgem os questionamentos elencados a seguir: Como os Resorts do complexo turístico do Porto das Dunas atendem aos requisitos do Sistema Brasileiro de Classificação dos Meios de Hospedagem (SBClass)? Qual a relevância da aplicação e execução dos requisitos do SBClass para os hóspedes que se hospedam nos resorts do complexo turístico do Porto das Dunas? Como a aplicação dos requisitos de serviços, infraestrutura e sustentabilidade em um empreendimento hoteleiro colabora para a avaliação dos hóspedes?

Para responder aos questionamentos anteriores, esse estudo tem como objetivo analisar os requisitos propostos para a classificação da tipologia resort no Sistema Brasileiro de Classificação de Meios de Hospedagem (SBClass) nos três empreendimentos hoteleiros, auto classificados de resorts, que compõem o complexo turístico do Porto das Dunas, que é compreendido por 03 empreendimentos.

Apesar do Sistema Brasileiro de Classificação de Meios Hospedagem (SBClass) ter sido utilizado nesse artigo como base para obtenção dos dados na pesquisa, é necessário informar que a SBClass não está mais vigorando no Brasil, devido a uma rigorosa burocracia para a obtenção da classificação hoteleira de estrelas, junto aos empreendimentos hoteleiros no país.

É importante ressaltar que o Sistema Brasileiro de Classificação dos Meios de Hospedagem (SBClass) ainda está em fase de reestruturação para se adaptar a atual realidade do setor hoteleiro do Brasil, estabelecendo dessa forma, uma comunicação direta pelas plataformas digitais e que principalmente se adeque à realidade dos empreendimentos encontrados nesse país, quanto a infraestrutura, recurso humano, serviços e sustentabilidade. 


\section{O SISTEMA BRASILEIRO DE CLASSIFICAÇÃO DE MEIOS DE HOSPEDAGEM}

À medida que a hotelaria passou a se expandir em todo o mundo, percebeu-se a importância, por meio de alguma maneira, de possibilitar aos turistas que buscavam se hospedar ter qualidade e comodidade em sua estadia. De acordo com Duarte (2005) surgiu a princípio na Europa, o sistema de classificação de hotéis, indicado por estrelas, o qual, posteriormente, veio a se expandir para todo o mundo. De maneira oficial, conforme Castelli (2003), a classificação dos meios de hospedagem ocorreu no final da década de 60, com o propósito de dar aos clientes a percepção do que estaria nos empreendimentos hoteleiros à espera deles, bem como possibilitar aos donos desses empreendimentos a percepção do que esses precisavam adequar para melhor atender e se enquadrar nos moldes propostos pelo padrão de estrelas. Sobre o uso das estrelas, Santos e Kadota (2012) ressaltam que voltou a vigorar em território nacional em 2010, com a criação do SBClass, após anos de indefinição do sistema de classificação hoteleira, o qual sofreu profundas alterações entre 1998 e 2002.

Em se tratando do sistema de classificação dos meios de hospedagem no Brasil, historicamente falando, ele tem evoluído consideravelmente, desde a década de 70, e passou a ser obrigatório em 1977, quando foi criada a Lei $\mathrm{n}^{\circ}$ 6.505. Em 1980, foi publicado o Decreto $\mathrm{n}^{\circ}$ 84.910, que regulamentou os dispositivos da Lei $\mathrm{n}^{\circ}$ 6.505, de 13 de dezembro de 1977, referentes aos meios de hospedagem de turismo e criou um capítulo exclusivo sobre a classificação dos empreendimentos. Já em 1991, a Lei no 8.181 deu ao Instituto Brasileira de Turismo (Embratur) a função de classificar os empreendimentos dedicados às atividades turísticas. Mas somente em 2002 foi divulgada a Deliberação Normativa n ${ }^{\circ} 429$, a partir da qual os meios de hospedagem passaram a ser classificados em categorias (Ministério do Turismo, 2014). Essas categorias são representadas por símbolos, as estrelas.

Diante das várias alterações pelas quais o sistema de classificação de hotéis foi passando ao longo dos anos, vários autores foram apresentando seus posicionamentos e classificações. Dessa forma, o MTur, com o objetivo de possibilitar a concorrência justa entre os meios de hospedagem do país e auxiliar os turistas, brasileiros e estrangeiros, em suas escolhas, optou por uma classificação padronizada, coerente com as diversidades dos tipos de meios de hospedagem e baseada em critérios técnicos, após realizar todo um processo de pesquisas e estudos. Assim, editou a Portaria $\mathrm{n}^{\circ}$ 100, de 16 de junho de 2011, a qual instituiu o Sistema Brasileiro de Classificação de Meios Hospedagem (SBClass), como estratégia para promover e assegurar a competitividade em um mercado global altamente disputado (Ministério do Turismo, 2010). 
Com a criação do SBClass, o MTur voltou-se para o propósito de atender à diversidade da oferta hoteleira nacional, estabelecendo, de forma participativa, em parceria com o Instituto Nacional de Metrologia, Qualidade e Tecnologia (Inmetro), a Sociedade Brasileira de Metrologia (SBM) e a sociedade civil, sete tipos de meios de hospedagem, sendo eles: Hotel, Resort, Hotel Fazenda, Cama \& Café, Hotel Histórico, Pousada e Flat/Apart-Hotel. O prérequisito para o empreendimento solicitar e participar do processo de classificação seria a regularidade do cadastro do Meio de Hospedagem no MTur, por meio do Cadastro dos Prestadores de Serviços Turísticos (Cadastur), um Sistema de Cadastro de pessoas físicas e jurídicas que atuam no setor do turismo, o qual foi criado em 2008, a partir do Plano Nacional de Turismo (PNT) 2007-2010.

Após verificação de cadastro junto ao MTur, a empresa interessada em receber a classificação poderia dar continuidade ao processo de classificação em uma das sete tipologias presentes no SBClass, com suas respectivas categorias. Para diferenciarem-se as categorias, adotou-se a consagrada simbologia de estrelas, porém estabeleceram-se requisitos específicos para cada tipologia, sendo eles: infraestrutura, serviços e sustentabilidade, os quais serão abordados, a partir de seus conceitos e especificidades.

Porém, é importante ressaltar que a aderência e aceitabilidade do SBClass pelo mercado hoteleiro não foi o suficiente para a sua continuidade, pelo fato da classificação hoteleira não se adequar a realidade hoje encontrada no país. Sendo assim, é pertinente dizer que há uma necessidade de obtenção de uma nova classificação hoteleira por parte do Ministério do Turismo (MTur), cuja importância será essencial para dar suporte técnico, de apoio e reconhecimento tanto do novo sistema hoteleiro, quanto da diversidade de hospedagens existentes no Brasil.

\section{OS REQUISITOS DE INFRAESTRUTURA, SERVIÇOS E SUSTENTABILIDADE DO}

\section{SBCLASS}

O SBClass estava fundamentado em uma série de requisitos a que os meios de hospedagem devem atender, sendo eles: infraestrutura, serviços e sustentabilidade. Tais requisitos são divididos em: Mandatórios (M), que possuem cumprimento obrigatório pelo meio de hospedagem; e Eletivos (EL), de livre escolha do meio de hospedagem, tendo como base uma lista pré-definida com tais requisitos para cada tipologia.

Os requisitos de infraestrutura, conforme vigorava o SBClass, estão vinculados às instalações e aos equipamentos, sendo ambos necessários a todos os empreendimentos 
hoteleiros. Os resorts, definidos conforme Ministério do Turismo (2010) é um hotel com infraestrutura de lazer e entretenimento que dispõe de serviços de estética, atividades físicas, recreação e convívio com a natureza no próprio empreendimento, apresenta a necessidade de cumprimento para possuir em sua infraestrutura uma diversidade de instalações e equipamentos que atendam aos requisitos solicitados.

Para a tipologia Resort, o SBClass estabelecia as categorias de quatro estrelas (mínimo) a cinco estrelas (máximo), o que se configura como o nível máximo para um empreendimento possuir, tendo em vista que, pelo SBClass, uma tipologia pode ter de uma a cinco estrelas, mas nem todas as tipologias classificadas dentro do Sistema atingem a todos os níveis, como é o caso dos resorts, que se destacam assim pela grande estrutura que possuem e pela diversidade de itens que dispõem em sua estrutura, em todos os requisitos.

Tal percepção a partir do requisito de infraestrutura, o qual apresenta a maior quantidade de itens na Matriz de Classificação, e está vinculado às instalações e aos equipamentos (Ministério do Turismo, 2010).

Na referida Matriz, os itens desse requisito são divididos em: Áreas comuns, Unidades Habitacionais (UH) e Alimentos e bebidas (A\&B). As áreas comuns (AC) estão relacionadas a todos os aspectos que são utilizados pelos hóspedes dentro do hotel de maneira coletiva: banheiros sociais, salas de reuniões, salas de ginástica, academias, toalhas para piscina, jornais, cadeiras de sol etc. Logo, precisam ser cuidados e preservados para o uso satisfatório de todos os hóspedes. Quanto a UH, “[...] é o espaço que compreende as áreas principais de circulação comuns do estabelecimento destinado à utilização pelo hóspede, para bem-estar, higiene e repouso" (Castelli, 2003, p. 57). Assim, tem-se como as AC a necessidade do cuidado com a limpeza, manutenção, decoração e outros pontos mais que são percebidos pelos clientes.

A área de $A \& B$, a qual, dentro da estrutura organizacional e funcional do hotel, de acordo com Castelli (2003), é a mais complexa. Para o autor, ela exige uma grande demanda de profissionais para executarem a mão de obra e, em contrapartida, pode ter um retorno financeiro menor do que o investimento feito. Assim, alguns hotéis optam por terceirizar essa área, o que pode não ser positivo, dependendo da empresa terceirizada.

No que se refere ao requisito de serviços, esses estão vinculados à oferta de serviços, sendo definido por Vieira (2004) como ações, ato que, diferentemente dos produtos, possuem um enfoque intangível, pois seu resultado ou produto final é sempre um sentimento, seja ele de satisfação ou não. Dessa forma, isso varia de pessoa para pessoa, isto é, cada cliente poderá ter uma reação diferente para um mesmo tipo de serviço. 
Mesmo que a tecnologia tenha se expandido e progredido consideravelmente nas empresas hoteleiras, o elemento humano permanece a atuar como imprescindível para a oferta dos serviços disponibilizados, ou seja, "[...] a demanda é humana, e a oferta depende fundamentalmente do elemento humano" (Castelli, 2003, p. 36), o qual necessita ser qualificado, a fim de garantir que o nível de serviços prestados seja o melhor possível. E as empresas que prestam serviços, a fim de serem competitivas, precisam investir na qualificação de seus colaboradores, por meio de treinamentos e educação.

Sobre o último requisito da Matriz de Classificação, têm-se os requisitos de Sustentabilidade, para o qual Ministério do Turismo (2010) explica que os requisitos de sustentabilidade estão vinculados ao uso de recursos, de maneira ambientalmente responsável, socialmente justa e economicamente viável, de forma que o atendimento das necessidades atuais não comprometa a possibilidade de uso pelas futuras gerações.

Para fortalecer as práticas sustentáveis no turismo, a adoção do requisito de sustentabilidade para compor o SBClass tem um relevante significado, uma vez que norteia os empreendimentos a adotarem padrões que condizem com os princípios socioambientais tão propagados e imprescindíveis para o bom desenvolvimento de uma empresa e dos colaboradores que nela atuam. Com o intuito de fortalecer o que já está proposto atualmente, a ABNT está desenvolvendo uma norma voltada para a sustentabilidade nos meios de hospedagem.

A partir da conceituação, da explanação e do aprofundamento acerca dos três requisitos que compõem o SBClass quando esteve em vigor, o referido estudo propõe-se a realizar uma análise de cada um deles a partir dos resorts do complexo turístico do Porto das Dunas. Assim, far-se-á a explanação dos procedimentos metodológicos da pesquisa e a respectiva apresentação e discussão dos resultados. 


\section{PROCEDIMENTOS METODOLÓGICOS}

Para o alcance do objetivo, houve a necessidade da inserção do pesquisador no ambiente de investigação, nos empreendimentos hoteleiros auto classificados de resorts pelo complexo turístico do Porto das Dunas. Dessa forma, optou-se pelos três empreendimentos, por serem os que se enquadram na tipologia resort e fazem parte de um complexo turístico reconhecido em todo o mundo, o qual possui o maior Parque Aquático da América Latina.

O reconhecimento do complexo turístico, enquanto categoria de resort possibilitou relacionar os requisitos do SBClass com a realidade encontrada nos estabelecimentos hoteleiros analisados neste trabalho, ou seja, o Porto das Dunas. Sendo assim foi necessário utilizar o recurso da análise documental como etapa inicial, uma vez que a partir das informações encontradas na cartilha resort, foi possível identificar se os empreendimentos citados atenderiam ou não aos requisitos propostos na classificação hoteleira.

A pesquisa classificou-se como documental, a qual, de acordo com Marconi e Lakatos (2016, p. 157), tem como característica: “[...] que a fonte de coleta de dados está restrita a documentos, escritos ou não, constituindo o que se denomina de fontes primárias". Além disso, conta com a utilização de fontes primárias e secundárias, as quais Schluler (2003, p. 83) define, respectivamente, como: “[...] as que provêm de organismos que realizaram as observações”; e “[...] quando se recorre a dados já publicados ou que, sem haver sido publicado, foram recompilados originalmente por outros". As fontes primárias resultaram de uma observação feita pelo pesquisador de determinado documento, neste caso, a cartilha resort e do ambiente virtual; e as fontes secundárias podem ser exemplificadas a partir dos estudos apresentados em congressos, seminários, publicados em periódicos, dissertações de mestrados, teses de doutoramentos, ou seja, material já publicado.

O estudo apresenta-se com visão crítica da realidade ao analisar os requisitos do SBClass quando o mesmo esteve em vigor nos empreendimentos hoteleiros do complexo turístico do Porto das Dunas, utilizando-se de uma abordagem qualitativa através dos critérios presentes na cartilha resort e a sua aplicabilidade nos empreendimentos citados anteriormente.

Sendo assim, as fontes primárias documentais usadas na referida pesquisa foram duas: a Matriz de Classificação dos Meios de Hospedagem - Tipologia Resort, do Ministério do Turismo (2010) e as 66 avaliações dos usuários postadas na plataforma do TripAdvisor.

Pelo fato de se tratar de um artigo que buscou coletar informações de três empreendimentos hoteleiros pertencentes ao completo turístico, esse trabalho se qualifica também como pesquisa de campo, por se tratar dos estabelecimentos que possuem como 
elemento principal a ser abordado “[...] o seu meio ambiente próprio” (Severino, 2007, p. 123), neste caso, os resorts.

Com a Matriz de Classificação dos Meios de Hospedagem - Tipologia Resort buscouse realizar uma explanação sobre os requisitos nela propostos e, assim, poder verificar e analisar quais deles existem nos resorts A, B e C do complexo turístico do Porto das Dunas, a partir de um levantamento feito com os gestores dos referidos empreendimentos. A referida Matriz é estruturada em 114, 65 e 13 itens, de infraestrutura, serviços e sustentabilidade, respectivamente. E esses se dividem em: Mandatórios (M) - obrigatórios e Eletivos (EL) opcionais. Para destacar a resposta nos itens existentes no resort, o gestor foi orientado a colocar um asterisco (*) ao lado do M ou EL, presentes nas colunas das categorias de 04 ou 05 estrelas da Matriz de Classificação.

O instrumento utilizado para coleta de dados na pesquisa de campo foi o questionário, que, de acordo com Severino (2007, p. 125), é: “[...] um conjunto de questões, sistematicamente articuladas, que se destinam a levantar informações escritas por parte dos sujeitos pesquisados, com vistas a conhecer a opinião dos mesmos sobre os assuntos em estudo". O questionário aplicado, separadamente, em cada um dos três resorts, constituiu-se de 10 perguntas, sendo que as 05 primeiras abordam sobre a classificação dos resorts; e as 05 últimas tratam sobre a percepção dos gestores em relação às avaliações dos hóspedes nas redes sociais.

A coleta de dados concretizou-se entre os dias 22 de março a 17 de abril de 2018, período em que efetivamente foi possível realizar a aplicação dos questionários com os gestores.

Após esta etapa, para confirmar dos dados coletados juntos aos resorts, julgou-se necessário analisar as opiniões dos clientes que se hospedaram nos empreendimentos estudados, a partir das avaliações postadas no site TripAdvisor, plataforma que possui “[...] 83,4 milhões de usuários únicos mensais, 2,8 milhões de usuários únicos mensais no Brasil, 125 avaliações por minuto, 2,8 mil tópicos publicados nos fóruns/dia” (Serviço Brasileiro de Apoio às Micro e Pequenas Empresas - Sebrae, 2015, p. 1).

Com o intuito de obter as informações essenciais após a aplicação dos questionários com os gestores e para seguir a análise dos dados foi utilizado o método Netnográfico, entendendo como “[...] uma ferramenta de pesquisa qualitativa que adapta as técnicas da abordagem etnográfica ao estudo de culturas e comunidades que estão surgindo através da comunicação mediada pelo computador (CMC)", (Kozinets, 2002 como citado em Correia, Alperstedt, \& Feuerschutte, 2017, p. 165). 
Trata-se de um método capaz de prover informações de simbolismos, significados e padrões de consumo de grupos de consumidores online. A netnografia implica em uma análise do papel das redes sociais nas respostas dos sujeitos envolvidos que postam suas avaliações.

Para Kozinets (2010), o método netnográfico deve seguir: a escolha de quais tópicos analisarem, saber selecionar uma amostra, detectar a identidade cultural dos indivíduos em foco e, por fim, fazer a coleta e análise de dados. Essa última pode ser feita a partir de tipos distintos de captura, que são:

- Dados coletados e copiados diretamente dos membros (usar filtros para otimizar a pesquisa);

- Informações das práticas comunicacionais dos membros;

- Dados levantados em entrevistas com membros por e-mails ou chats;

- Relatório e feedback dos pesquisados.

Nessa perspectiva, foram pesquisadas, no site TripAdvisor (2018), as opiniões/avaliações dos clientes que já se hospedaram nos resorts do complexo turístico do Porto das Dunas. Primeiramente, selecionou-se no filtro "Época do ano" o período de dezembro a fevereiro (Dez-Fev), tendo em vista que corresponde ao período de alta estação e vislumbrase encontrar muitas avaliações relativas ao período. Contudo, a partir do momento em que se começou a fazer a leitura e a análise das avaliações, percebeu-se de forma recorrente reclamações pertinentes às reformas que estavam ocorrendo nos resorts.

E o foco dos hóspedes nesse fato, nas avaliações postadas, não gerava comentários relativos aos requisitos propostos para análise: os serviços, a infraestrutura e a sustentabilidade. Então, já sabendo que o período seguinte disponível no filtro "Época do ano" seria de Março a Maio (Mar-Mai) e que já haviam nesses meses ocorridos várias melhorias e as reformas estariam mais próximas do fim, como informado nas páginas de cada resort, acreditava-se que se conseguiria coletar mais informações referentes aos requisitos nas avaliações feitas pelos hóspedes, daí a escolha pelo período de março a maio de 2018.

O levantamento das avaliações foi realizado no período de março a maio de 2018 , sendo feito de forma separada para cada um dos resorts. É importante ressaltar que, seguindo os passos propostos por Kozinets (2010), opta-se por fazer um filtro das avaliações que se deseja analisar no site, sendo ele "Época do ano" - meses de março a maio, e "Idioma" - Português, conforme mostra a Figura 1: 
Figura 1 - Filtros para seleção de avaliações no TripAdvisor

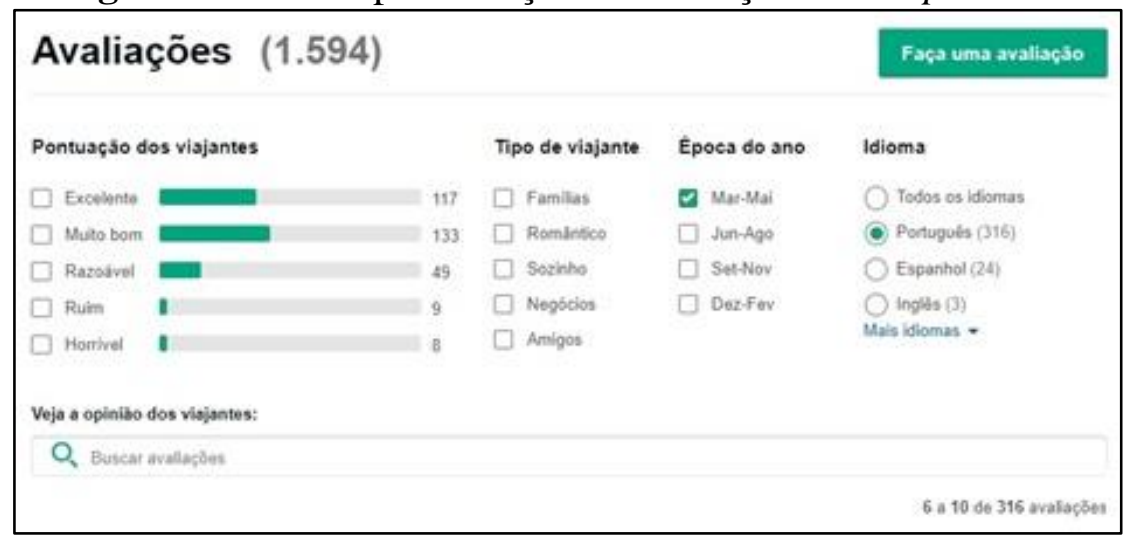

Fonte: TripAdvisor, 2018.

Com essa filtragem, obteve-se um total de 316, 179 e 276 avaliações para os resorts A, B e C, respectivamente. No entanto, observando as avaliações após ter selecionado o filtro “Época do ano", percebeu-se que o TripAdvisor apresenta avaliações de todos os anos para o período de março a maio, desde que o resort começou a fazer parte do site. Assim, tem-se, na ordem, para os resorts A, B e C, avaliações desde: março a maio de 2012; maio e abril de 2013; e março e maio de 2013. Dessa forma, optou-se em fazer uma análise somente das avaliações referente a março, abril e maio de 2018, devido aos dados serem os mais atuais. Como já explicitado, foi feito um levantamento das avaliações realizadas somente nesse período. Primeiro, selecionou-se a opção "Veja as avaliações mais recentes" que fica disponível logo abaixo do total de avalições feitas para o resort na Figura 2 a seguir:

Figura 2 - Opção para ver avaliações no TripAdvisor

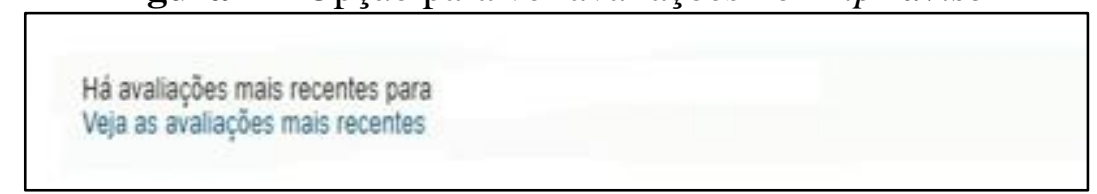

Fonte: TripAdvisor, 2018.

Mas, quando se seleciona o filtro "Época do ano" - março a maio, essa opção desaparece da página. Então, a opção para coletar as avaliações do período desejado foi a partir da verificação individual de todas as opções presentes no filtro "Pontuação de viajantes": excelente, muito bom, razoável, ruim e horrível. Após feito isso, chegou-se ao número de avaliações postadas nos meses de março a maio de 2018 para os resorts A, B e C, que totalizaram 66, sendo respectivamente, para cada resort: 25, 22 e 19 avaliações, conforme apresentado no ficando $95 \%$ compreendidas nas pontuações: excelente, muito bom e razoável; e somente 5\% na pontuação: ruim e horrível como apresenta o Quadro 1 abaixo: 
Quadro 1 - Quantidade de avaliações para os resorts A, B e C de março a maio de 2018 no

TripAdvisor

\begin{tabular}{|l|c|c|c|}
\hline \multicolumn{1}{|c|}{$\begin{array}{c}\text { Pontuação de } \\
\text { Viajantes }\end{array}$} & Resort A & Resort B & Resort C \\
\hline 1. Excelente & 10 & 10 & 06 \\
\hline 2. Muito bom & 09 & 08 & 08 \\
\hline 3. Razoável & 06 & 03 & 03 \\
\hline 4. Ruim & - & 01 & 01 \\
\hline 5. Horrível & - & - & 01 \\
\hline Total & 25 & 22 & 19 \\
\hline
\end{tabular}

Fonte: Pesquisa direta, 2018.

A partir desse resultado, foram analisadas todas as 66 avaliações feitas no TripAdvisor para os resorts A, B e C até o dia 02 de maio de 2018, data em que foram realizadas, pelo pesquisador, as análises das referidas avaliações.

Em todas as avaliações há informações importantes: nome e imagem do usuário do TripAdvisor (mantidos nessa pesquisa confidenciais, devido à ética de pesquisa na netnografia); data em que o cliente avaliou; tema dado pelo cliente à avaliação; texto descritivo; feedback de agradecimento do TripAdvisor, com um emotion (curtiu), seguido de uma breve explicação do site sobre a avaliação postada: "Esta avaliação representa a opinião subjetiva de um membro do programa TripAdvisor e não da TripAdvisor LLC."; e, por fim, o feedback do Gerente Geral do resort no TripAdvisor, conforme a Figura 3 a seguir:

Figura 3 - Modelo de Avaliação no TripAdvisor

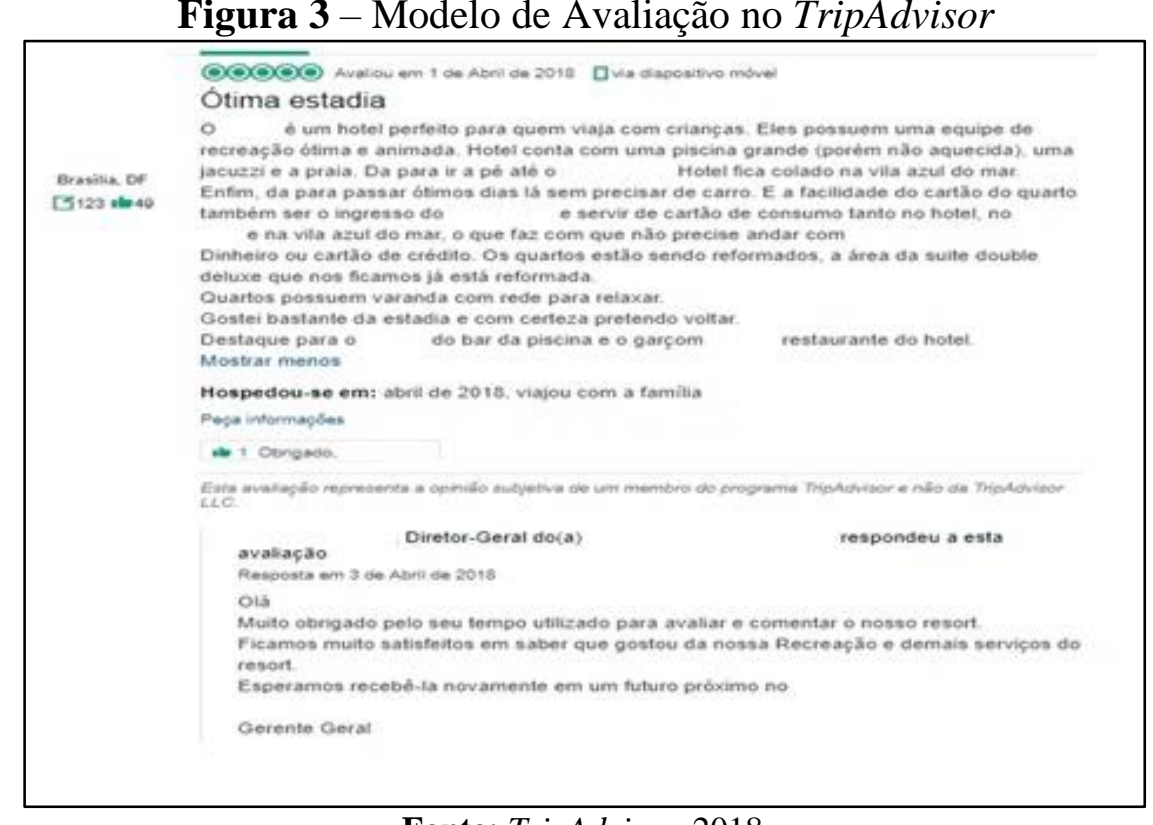

Fonte: TripAdvisor, 2018.

Terminada a análise das avaliações no TripAdvisor, foi possível fazer a verificação dos dados apresentados pelos gestores no questionário e Matriz de Classificação aplicados, a partir 
da percepção dos hóspedes, o que pode ser constatado no tópico que segue, o qual trata sobre os resultados encontrados e as suas respectivas discussões.

\section{RESULTADOS E DISCUSSÕES}

Para dar prosseguimento ao texto, divide-se em duas partes e posteriormente uma análise geral com cruzamento dos dados, dos levantamentos e das análises do TripAdvisor. A primeira se refere aos questionários aplicados; e a segunda, relacionada à análise das avaliações no TripAdvisor.

Partindo da análise das dez respostas do questionário aplicado, em cada um dos três resorts, tem-se, primeiramente, a análise das respostas dadas às cinco primeiras perguntas, as quais abordam sobre a classificação dos resorts. Assim, tem-se como resultado da pergunta 01 que: os três resorts são apresentados por seus gestores como sendo da categoria de quatro estrelas, o que, de acordo com eles, é uma definição dada por parâmetros em modelos de hotéis da mesma tipologia, e também de quatro estrelas. Diante dessa primeira resposta, fica evidenciado o caráter de independência que os hotéis apresentam em relação à classificação oficial do MTur, pois se auto classificam como resorts e com quatro estrelas.

Para verificar essa percepção sobre o aspecto da independência, é questionado na pergunta 02 se o resort possui cadastro regular no Cadastur, sendo esse obrigatório para todas as empresas pertencentes ao setor do turismo. A resposta obtida foi a de que o grupo no qual os empreendimentos estão inseridos tem cadastro no Cadastur, mas com validade até outubro de 2017, e não foi possível fazer a renovação imediata, devido a pendências no CNPJ de uma das empresas do Grupo. Os gestores relataram o empenho da empresa em resolver todas as pendências, a fim de fazer a atualização do Cadastur.

Após a verificação do cadastro dos resorts no Cadastur, tem-se a pergunta 03, a qual interroga se o resort já foi classificado por algum Sistema de Classificação Oficial do Governo. A resposta foi negativa para todos os empreendimentos, sendo apresentado como motivo o fato de que há por parte da diretoria a escolha em modelo de negócio com base nos hotéis quatro estrelas, de dentro e fora do Brasil.

Expandindo a pesquisa, foi questionado, na pergunta 04 se o gestor já conhece ou ouviu falar sobre o SBClass. Como resposta, um deles disse não conhecer o sistema, e os outros dois disseram que a informação obtida em 2017 era a de que o SBClass estava momentaneamente desativado.

Para dois dos três gestores que participaram da pesquisa o SBClass não teve aceitabilidade no mercado hoteleiro nacional devido a burocracia no processo de regularização 
bem como as etapas para se obter a classificação por estrelas, por isso o motivo da sua não aderência ou aceitabilidade como meio de reconhecimento, classificação e fiscalização dos estabelecimentos hoteleiros no país.

Diante dessa última informação, foi feita uma nova investigação, a fim de averiguar a real situação do sistema confirmava as falas de dois dos três gestores, uma vez que a página visitada do SBClass, na qual foi acessado o link "Lista dos Classificados", em que aparece a seguinte mensagem "Não há meios de hospedagem com o certificado de classificação válido no âmbito do SBClass" (Ministério do Turismo, 2018).

Frente a essa informação, ficou a dúvida se os meios de hospedagem passariam por uma atualização cadastral no ano de 2018, então foi enviada a solicitação dessa informação ao email: atendimento.cgqt@ turismo.gov.br, do qual não se obteve retorno. Assim, aprofundandose na pesquisa, foi possível chegar à referida minuta, de 17 de fevereiro de 2017, de Projeto de Lei com propostas que alteram a Lei n. 11.771 (2008), de 17 de setembro de 2008, que confirma a desativação do SBClass:

[...] detectou-se que a forma de classificação realizada pelo Governo Federal não estava de acordo com a dinâmica de consumo dos brasileiros e, tampouco, com as referências de classificação utilizada pela iniciativa privada nacional e internacional. Foram investidos cerca de dez milhões de reais no SBClass. E de um universo superior a vinte e cinco mil meios de hospedagens existentes no País, há, hoje, apenas 59 efetivamente classificados [...]. Diante disso, optou-se por desativar o Sistema de classificação (SBClass) e transformar as matrizes de classificação existentes em material orientador, e, do mesmo modo, resolveu-se estudar novas tipologias, a exemplo de hotel boutique, hotel selva e albergues, desenvolvendo critérios e matrizes para servir de referência para o mercado (Ministério do Turismo, 2017).

Evidencia-se, diante dessa constatação, a relevância da verificação das informações coletadas no momento das entrevistas realizadas, à medida que eles acabam proporcionando novos resultados e, consequentemente, perspectivas para outras pesquisas. $\mathrm{O}$ fato de saber que o SBClass está desativado certamente foi importante, até para que a informação seja confirmada com os gestores que prestaram parte de seu tempo para as respostas do questionário do trabalho em questão.

É interessante observar, ainda, da citação apresentada na minuta, o trecho que diz sobre um universo superior a vinte e cinco mil meios de hospedagens existentes no País, há, hoje, apenas 59 efetivamente classificados (Ministério do Turismo, 2017). Ou seja, de 2011 até 2017, foram sete anos de atuação do SBClass e o resultado foi mínimo, o que expressa sua repercussão nos meios de hospedagem realizada de maneira inexpressiva. Inclusive, um dos gestores informou não conhecer o Sistema perguntou se era necessário pagar algum valor para se 
cadastrar, e a resposta foi positiva. O valor cobrado para ser feita a vistoria e ser dado o Certificado pelo SBClass tem preços determinados e cobrados por empreendimento.

O fato de descrever essa repercussão inexpressiva foi ainda enfatizado quando se analisa a resposta dos outros dois gestores que tinham conhecimento sobre o sistema a partir dos meios de comunicação, da experiência hoteleira e de pesquisa realizada no site do Ministério do Turismo. Mas em nenhum momento é citado que foi feito contato por parte de representantes do Mtur, responsáveis pelo SBClass, para realizar a classificação dos resorts, sendo eles pertencentes ao Complexo Turístico do Porto das Dunas, conhecido dentro e fora do Brasil.

Apesar dos resorts do complexo turístico do Porto das Dunas não terem nenhuma Classificação Oficial do Governo, mais especificamente o SBClass quando o mesmo estava em vigor, desde sua implantação até sua desativação, o que durou sete anos, é importante observar que mesmo os três estabelecimentos hoteleiros não fazendo parte de nenhuma classificação conseguem atender a uma das cartilhas da matriz do SBClass denominada de Resort, o resultado foi obtido a partir da análise documental e aplicação em campo dos questionários, conforme o método netnográfico possibilitou obter as informações necessárias, seguindo os respectivos itens, mandatórios e eletivos, nos três resorts estudados.

A partir de então, foi possível obter uma análise dos itens a ser seguidos na cartilha da Matriz de Classificação do SBClass para Resort e que foram consequentemente encontrados nos três estabelecimentos hoteleiros. Tem-se o quantitativo total de itens apresentados para cada requisito, bem como a exposição detalhada da quantidade de itens: Mandatórios (M), Eletivos (EL) e os que Não se Aplicam (NSA) à tipologia de resort quatro estrelas, expostos no Quadro 2 abaixo:

Quadro 2 - Divisão do quantitativo de itens da Matriz do SBClass - Tipologia Resort (4 estrelas)

\begin{tabular}{|l|c|c|c|c|}
\hline \multicolumn{1}{|c|}{ REQUISITOS DA MATRIZ } & TOTAL & M & EL & NSA \\
\hline 1. INFRAESTRUTURA & 114 & 88 & 22 & 04 \\
\hline 1.1 Áreas comuns (AC) & 47 & 38 & 07 & 02 \\
\hline 1.2 Unidades habitacionais (UH) & 60 & 45 & 14 & 01 \\
\hline 1.3 Alimentos e Bebidas (A\&B) & 07 & 05 & 01 & 01 \\
\hline 2. SERVIÇOS & 65 & 36 & 24 & 05 \\
\hline 3. SUSTENTABILIDADE & 13 & 08 & 05 & -- \\
\hline
\end{tabular}

Fonte: Elaborado pelos autores, 2018.

A partir da visualização do Quadro 2 no qual, somando-se todos os itens da matriz, temse um total de 192, fica óbvio que o requisito de infraestrutura é o que mais possui itens solicitados, com representatividade de 59\% dos itens, os quais ficam divididos em: áreas comuns, UH e A\&B. Posteriormente, apresentam-se os serviços, requisito com $34 \%$ dos itens 
que compõem a matriz; e finalmente, tem-se o requisito de sustentabilidade, o que tem a menor representatividade, com apenas $7 \%$ dos itens de toda a Matriz. Tendo como intuito fazer uma apresentação dos dados quantitativos do referido quadro de forma mais real, elabora-se o Quadro 03 no qual é mostrado o quantitativo dos itens de cada requisito da matriz do SBClass que existe em cada um dos resorts pesquisados, após verificação junto aos gestores de cada resort. Para cada resort foi utilizada na tabela uma letra que o representa: A, B e C.

Quadro 3 - Quantitativo de itens da Matriz do SBClass - Tipologia Resort aplicados aos Resorts A, B e C

\begin{tabular}{|l|c|c|c|c|c|c|c|c|c|}
\hline REQUISITOS DA MATRIZ & TOTAL & $\mathbf{M}$ & $\mathbf{A}$ & $\mathbf{B}$ & $\mathbf{C}$ & $\mathbf{E L}$ & $\mathbf{A}$ & $\mathbf{B}$ & C \\
\hline 1. Infraestrutura & 114 & $\mathbf{8 8}$ & & & & $\mathbf{2 2}$ & & & \\
\hline 1.1 Áreas comuns (AC) & 47 & $\mathbf{3 8}$ & 35 & 35 & 35 & $\mathbf{0 7}$ & 02 & 03 & 03 \\
\hline 1.2 Unidades habitacionais (UH) & 60 & $\mathbf{4 5}$ & 40 & 40 & 41 & $\mathbf{1 4}$ & 03 & 03 & 04 \\
\hline 1.3 Alimentos e Bebidas (A\&B) & 07 & $\mathbf{0 5}$ & 03 & 04 & 03 & $\mathbf{0 2}$ & 02 & 00 & 00 \\
\hline 2. Serviços & 65 & $\mathbf{3 6}$ & 30 & 30 & 30 & $\mathbf{2 4}$ & 15 & 16 & 16 \\
\hline 3. Sustentabilidade & 13 & $\mathbf{0 8}$ & 08 & 08 & 08 & $\mathbf{0 5}$ & 01 & 00 & 00 \\
\hline
\end{tabular}

Fonte: Elaborado pelos autores, 2018.

Frente à análise realizada sobre todos os aspectos do requisito de infraestrutura, é possível evidenciar que, dos 91 itens obrigatórios da matriz para classificar o empreendimento em resort quatro estrelas, os três resorts estudados apresentam um percentual médio de $86 \%$ dos itens de infraestrutura presentes em suas instalações, o que se destaca com um índice representativo, levando-se em conta o fato de os resorts não a terem usado como parâmetro de referência, e sim outros hotéis da mesma categoria no Brasil. A partir de um cenário real, entende-se que os itens da matriz foram elaborados de forma coerente para a tipologia em estudo.

Acerca da explanação sobre o quantitativo de itens relativos ao requisito de serviços, tem-se uma igualdade nos resultados encontrados, à medida que, dos 36 itens obrigatórios.

Considera-se relevante ressaltar que o quantitativo de itens do requisito serviços que existem nos resorts atendem a um percentual de $83 \%$ do total que está presente na Matriz de classificação. Compreende-se que é um índice considerável, levando-se em conta que os resorts não utilizaram a matriz como parâmetro para a implantação dos serviços, mas, de forma comparativa, possuem a maior parte do que ela propõe para a existência deles nos empreendimentos da tipologia em estudo.

Com os percentuais de $86 \%$ de atendimentos aos itens obrigatórios para o requisito de infraestrutura e $83 \%$ para os itens do requisito de serviços, os empreendimentos hoteleiros não estariam classificados pelo MTur como resort, visto que precisariam atender a $100 \%$ de todos os itens obrigatórios propostos pela matriz de classificação. 
No terceiro requisito da matriz, sustentabilidade, para o qual se tem um índice de $100 \%$ dos itens mandatórios presentes nos três resorts. Esse é o requisito com uma menor quantidade de itens, apenas 13 no total, e 08 mandatórios. Entretanto, a atenção para esses, que são obrigatórios, faz toda uma diferença para o desenvolvimento sustentável da empresa, abrangendo toda sua estrutura, visto que as medidas são permanentes em distintos âmbitos, que possuem fundamentação em alguma prática desenvolvida não somente pelos resorts pesquisados, mas por todo o complexo turístico do Porto das Dunas. Inclusive, ainda sobre a pergunta 05 do questionário, houve a resposta que os resorts foram certificados também pela ISO 14001 (2018), a qual se refere ao Sistema de Gestão Ambiental, tomando por base a ISO 14000.

Frente às ações de sustentabilidade presentes no complexo turístico do Porto das Dunas (incluindo os hotéis, o restaurante da praia e o parque aquático), destacando-se as iniciativas de uso sustentável dos recursos naturais, consumo consciente da água e energia, destinação adequada dos resíduos, prevenção da poluição, qualificação de seus colaboradores e processo que visam à melhoria contínua dos processos de gestão, evidencia-se a liderança de todo o complexo no desenvolvimento socioambiental do Porto das Dunas.

A análise das respostas dadas às 05 primeiras perguntas parte-se para as outras 05, as quais fazem uma abordagem da percepção dos gestores em relação às avaliações dos hóspedes nas redes sociais.

Na pergunta 06, é questionada qual a opinião do responsável (ou responsáveis) pelo resort sobre os sites que classificam os meios de hospedagem mediante as avaliações dos usuários (TripAdvisor, Decolar, Booking). As respostas obtidas foram as seguintes: “É um ótimo mecanismo para sabermos a opinião dos hóspedes sobre o resort", e "Acreditamos que é uma oportunidade boa de sabermos a visão do cliente e podermos melhorar os pontos fracos e falhas cometidas".

Esse posicionamento por parte dos gestores reflete o quão importante é a adoção do marketing digital por parte das empresas. Logo, com a crescente busca de informações turísticas na internet, tornam-se importante para os empreendimentos hoteleiros, restaurantes, agências de viagens e atrativos de maneira geral planejarem estratégias de marketing digital.

Na pergunta 07, é questionado se o responsável (ou responsáveis) pelo resort acredita que o fato das avaliações desses sites (TripAdvisor, Decolar, Booking) serem subjetivas (emocional, parcial) mudaria a avaliação, no sentido de desqualificá-la. Para essa, a resposta, em comum, obtida dos gestores foi a de que "Na maioria dos casos, mesmo o cliente agindo na emoção é possível analisar e comparar com a realidade e tirar o que é passivo de melhorias". 
Assim, percebe-se a importância dada às avaliações feitas pelos clientes no meio virtual e tal atenção pode ainda ser reafirmada a partir da resposta dada à pergunta 08, quando foi questionado se o resort se baseia nos comentários da internet para melhorar sua infraestrutura e seus serviços. Obteve-se o sim como resposta para todos os empreendimentos, sendo ressaltado pelos gestores que é utilizado como padrão para todos os resorts a plataforma do TripAdvisor na qual: "Os perfis empresariais têm que ser negócios que atuam no segmento de acomodações, restaurantes ou atrações e são cadastrados como locais permanentes, e para participar da rede, têm que estar enquadrados em diretrizes específicas da plataforma" (Sebrae, 2015, p. 2).

Na pergunta 09, é questionado se o resort dá algum feedback para as avaliações dos clientes realizadas nos sites de avaliação. A resposta obtida por todos os gestores foi uma só, “sim”, sendo destacado que "esse feedback acontece, de um ano para cá, diariamente para todos os comentários postados na página do TripAdvisor, site que é utilizado oficialmente por todos os resorts". Outro site em que são dados feedbacks imediatamente, caso surja demanda, é o "Reclame aqui".

Tal atitude realizada pela gestão dos resorts apresenta-se, conforme Esteves (2011), como uma estratégia de marketing online, a qual visa à satisfação do consumidor pós-consumo, a partir de um tratamento personalizado destinado a cada um deles, quando respondidas às avaliações de maneira individualizadas.

Diante desse questionamento, com sua respectiva resposta, percebe-se a necessidade de fazer uma análise das avaliações postadas pelos hóspedes no site do TripAdvisor, nos três resorts, de maneira individual para cada empreendimento, seguindo-se a respectiva ordem dos resorts: A, B e C.

Para todas as análises, relembra-se que foi feito um filtro sobre a época do ano, concentrando-se nas avaliações da época de março a maio de 2018, para o idioma português. A partir de tal filtragem, obteve-se um resultado de 66 avaliações feitas no TripAdvisor para os resorts $\mathrm{A}, \mathrm{B}$ e C, ou seja, foram analisadas as opiniões de 66 pessoas, mas essas opiniões foram realizadas para os três resorts, sendo 25 para o resort A, 22 para o resort B e 19 para o resort C, no período selecionado para análise.

A partir das avaliações postadas pelos hóspedes no período selecionado, foram analisados os aspectos pertinentes aos requisitos estudados: infraestrutura, serviços e sustentabilidade. Pelo fato de não haver um parâmetro para seguir, optou-se por retirar de cada uma das postagens feitas pelos hóspedes os adjetivos que atribuíam aos aspectos relacionados aos requisitos de estudo. 
Primeiramente, foi feito o levantamento dos requisitos de infraestrutura (IE), no âmbito das áreas comuns (AC). Foram elencados todos os locais considerados como áreas comuns citados pelos hóspedes em suas avaliações: hotel, piscinas, acesso ao parque, vila azul, copa kids, área de lazer, academia, estacionamento, localização, sala de jogos e brinquedoteca, de cada um dos resorts.

Das 66 pessoas que avaliaram as áreas comuns dos três resorts, houve um total de 73 atribuições, tendo em vista que algumas delas se repetem em diferentes postagens. Por exemplo: qualificar o hotel A em "ótimo" se repete em duas postagens, e assim por diante. Dessas 73 atribuições, 31 foram positivas em relação ao hotel de maneira geral (para os três resorts), o que representa um percentual de $47 \%$ dos aspectos atribuídos aos resorts. Para as áreas comuns, foram citados nas avaliações para os três resorts: o hotel, sempre comentado pelos hóspedes com adjetivos que o qualificam: ótimo, confortável, maravilhosos (adjetivo comum para os três resorts) etc.

As atribuições positivas dadas pelos hóspedes têm um significado bastante relevante quando feita a comparação com os itens apontados como existentes nos resorts, a partir da Matriz de Classificação, que possui 92\% dos itens obrigatórios das AC presentes nos três resorts. Logo, confirma-se a informação diante da análise das avaliações do TripAdvisor, as quais ainda reforçam essa constatação pela maioria dos títulos postados pelos hóspedes nos assuntos das avaliações, os quais são positivos, a exemplo: "Voltaremos - expectativas superadas", "Estadia maravilhosa", "Muito boa estrutura".

Essa sequência de adjetivos que qualificam as áreas $\mathrm{AC}$ dos resorts também é feita nas avaliações das UH: confortáveis, limpas, espaçosas, reformadas, ótimas e agradáveis.

Do levantamento das avaliações para os Resorts A, B e C no TripAdvisor - Requisito Infraestrutura - Unidades Habitacionais (UH), obteve-se, das 66 avaliações postadas, 45 atribuições feitas às $\mathrm{UH}$, sendo todas positivas. Isso reflete o nível de qualidade que as UH possuem na percepção dos hóspedes, o que é confirmado pelos empreendimentos quanto ao atendimento dos itens obrigatórios existentes de acordo com a Matriz de Classificação, 88\% deles.

Finalizando a análise do requisito de infraestrutura na percepção dos hóspedes, tem-se o item pertinente ao setor de A\&B, o qual foi dividido, a partir das avaliações no TripAdvisor, em: restaurante, refeições e preços. Obtiveram-se como resultado alguns adjetivos para restaurante: excelente, perfeito, ambiente incrível, ponto fortíssimo do resort, cardápio gourmet para todos os gostos. Para refeições: maravilhosas, fantásticas, deliciosas, muito boas, bastante 
variadas, sempre muito saborosas. E para preços: abusivos, exorbitantes, altos, muito caros, exagerados, bem caros, um pouco caros.

Houve das 66 postagens realizadas, 64 comentários referentes à $A \& B$, os quais ficaram divididos: 18 para o aspecto restaurante; 21 para o aspecto refeições; e 25 para o aspecto preço. Sobre o restaurante e as refeições, das 39 pessoas que comentaram somente duas atribuições foram negativas, e as outras 37 foram positivas, teceram elogios no que diz respeito aos três resorts. Já no que se refere a preços, do total de 25 pessoas que comentaram para os três resorts, $100 \%$ foram comentários negativos, com a atribuição de adjetivos pejorativos, havendo observação de apenas dois hóspedes sobre: o quanto "vale a pena a experiência", mesmo os preços sendo expressivos; e, a "qualidade incontestável”, ainda que os preços sejam salgados.

Logo, é possível observar sobre os itens: restaurante e refeições, considerando-se restaurante, de acordo com Castelli (2003) o estabelecimento que fornece ao público alimentação mediante pagamento, que ambos mantêm a confirmação dada pelos resorts em comparação com o atendimento à Matriz de Classificação, a qual é dada pelos hóspedes nas avaliações que apresentam características positivas, tanto para a estrutura do restaurante: excelente, perfeito, cardápio variado (comum para os três resorts) etc.; como para a qualidade das refeições servidas: maravilhosas (comum para os três resorts), fantásticas, deliciosas etc. Excetua-se dessas somente um comentário para o resort $\mathrm{C}$, sobre possuir fila de espera.

Em contrapartida, no item relativo a preços, os comentários são, em sua totalidade, negativos, nos três resorts, aparecendo no total de 13, 05 e 07 vezes nas avaliações, o que representa o percentual de $52 \%, 36 \%$ e $22 \%$ de reclamações da totalidade das avaliações feitas.

Relacionado a esse ponto, na pergunta 10, é colocada a seguinte questão: verificando os feedbacks dos gerentes de cada resort no site TripAdvisor, há posicionamentos sobre os comentários realizados. Contudo, no que se refere ao fator "preço de alimentos e bebidas", não há um posicionamento para o hóspede, isso se dá por algum motivo específico? As respostas foram reunidas, apresentando-se, da seguinte maneira: “A política de preço é determinada pela empresa, os gerentes não têm permissão para falar sobre isso com os clientes, é uma decisão da mesma em não abrir essa discussão publicamente, pois não há interesse em diminuir os valores, consideramos uma forma de selecionar o público".

Analisando essa resposta, faz-se necessário destacar que, por terem a repercussão de avaliações postadas nas redes sociais de maneira tão enfática, e por receberem as avaliações dos clientes, o foco deveria ser no interesse dos clientes, em suas expectativas, e não em utilizar o preço como uma forma de seleção do público, mas verificar as possibilidades de que ele não seja um fator tão recorrente para reclamações. Quando é colocado por um dos gestores que "Há 
sempre comentários, para os quais o gerente analisa e busca correções”, deveria ser levado em conta esse aspecto, foco de tantas reclamações.

Diante dessa análise, é nítido que os pontos positivos devem ser mantidos, no âmbito da qualidade do ambiente e das refeições servidas. Contudo, no que se refere aos preços, frente ao quantitativo de críticas apresentadas pelos hóspedes, o resort poderia fazer uma análise sobre esse aspecto, partindo dos custos de cada prato ou bebida.

Tal análise poderia auxiliar na tomada de decisões que se direcione a satisfação do cliente, também sobre o quesito dos preços, a fim de observar se realmente é válido mantê-los como estão, sendo um ponto citado, de maneira tão recorrente pelos hóspedes, inclusive alguns relatam não comer ou beber nos resorts pelo fato de considerarem os preços muito altos, ou até fora da realidade, como citado em algumas avaliações.

Agora, parte-se para a análise das avaliações no requisito Serviços, que apresenta todos os itens citados e categorizados pelos hóspedes. Das 66 avaliações nos três resorts, houve um total de 101 atribuições feitas pelos hóspedes. Esse quantitativo se dá pelo fato de que são mencionados nas avaliações: funcionários, atendimento, beach friends, segurança, camareiras, cartão para consumo, monitores do kids club, vila azul, guias, estadia, parque, camareiras e internet; todos relacionados aos serviços prestados nos resorts. Para todos eles, com exceção da internet, citada nos resorts A e B como "Intermitente, sem funcionar nas áreas comuns"; e no atendimento, citado no resort C que "Houve falhas", há somente comentários e adjetivos positivos, os quais se repetem para os resorts $\mathrm{A}, \mathrm{B}$ e $\mathrm{C}$ - em funcionários, atendimento, beach friends e segurança.

Dos que são comuns a todos os resorts, destacam-se: os funcionários, chamados nas empresas de colaboradores; e os beach friends, que aparecem citados em, respectivamente, $29 \%$ e $25 \%$ das avaliações. Essa representatividade é bastante significativa, tendo em vista que os funcionários que desempenham todas as atividades do empreendimento, desde sua reserva até o momento de seu checkout. Assim, Castelli (2003, p. 127), ao falar sobre perfis de organizações empresariais, enfatiza a respeito do "[...] momento da verdade, que é aquele espaço de tempo em que os clientes interagem com algum aspecto da empresa e dessa interação obtêm um resultado positivo ou negativo".

No resultado para "Funcionários", as características atribuídas a eles em todos os resorts são positivas: atenciosos, gentis, excelentes, educados, agradáveis, solícitos, simpáticos, dedicados, eficientes, disponíveis, proativos etc. Isso confirma a boa imagem obtida do serviço por meio das avaliações, de maneira ampla, ou seja, os colaboradores destacaram-se nos momentos da verdade que tiveram com os clientes em momentos e situações distintos. 
Sobre o setor da recreação e animação, é imprescindível para entreter e fazer com que o hóspede tenha atividades durante todo o tempo dentro do hotel, uma vez que quando bem planejada e organizada tem o intuito da diversão, assim como, do desenvolvimento da capacidade física dos participantes (Appelt \& Lopes, 2006).

Quanto aos recreadores ou animadores, Corrêa (2002) ressalta que esses profissionais são muitos requisitados nos hotéis de lazer pelos hóspedes, sendo que o seu papel destes é de promover a integração entre os clientes, os quais sem a imediação dos animadores não o fazem. Tal exigência se dá pelo fato de que a função desses profissionais é de extrema relevância para o tempo de permanência dos hóspedes nos empreendimentos em questão, tendo em vista que os clientes passam a maior parte do tempo dentro do resort.

Essa colocação feita pelo autor reflete de forma muito semelhante a muitos dos comentários lidos nas avaliações sobre "os tios", mencionados em todos os resorts: "A equipe de animação é fantástica, independente da sua idade, dos 02 aos 80", “Os monitores são muito animados e estão sempre disponíveis", "Melhor equipe de recreação, os beach friends mais incríveis que já conhecemos" (são citados nesse comentário os nomes de todos os "tios"), como são chamados os animadores, para haver um maior vínculo, principalmente com as crianças.

No que se refere ao requisito de serviços, diante dos dez pontos relatados como positivos pelos hóspedes em suas avaliações no TripAdvisor, torna-se evidente que a satisfação é obtida pelos hóspedes nos resorts $\mathrm{A}, \mathrm{B}$ e $\mathrm{C}$, tendo muitos dos aspectos citados por eles presentes nas funções elencadas pelo autor, bem como na confirmação, por parte dos resorts, ao atendimento dos itens presentes na Matriz de Classificação, $83 \%$ no total.

$\mathrm{Na}$ análise de todos os requisitos, chega-se ao da sustentabilidade, para o qual o único aspecto citado, nos três resorts, que tem relação com o meio ambiente é a referência feita em alguns das avalições à praia, colocando que é: "muito bem cuidada, excepcional, exclusiva, muito boa, bem tranquila, espetacular, linda e belíssima." Mas, sobre as medidas permanentes para redução do consumo, em todos os âmbitos, reciclagem e reutilização de materiais ou outro aspecto que se refira a questões sustentáveis nos empreendimentos, não é feita nenhuma menção por porte dos hóspedes em suas avaliações.

Entretanto, o fato de ser mencionada a praia como bem cuidada e todos os outros adjetivos que recebeu em todos os resorts, já pode ser considerado uma percepção do hóspede sobre os aspectos ambientais atrelados aos empreendimentos, tendo em vista que os comentários são feitos nas avaliações desses resorts. Acredita-se que, se houvesse algum aspecto ambiental que vissem, de forma nítida, como errado, comentariam, como bem fundamenta a Revista Hotéis (2016), que divulgou em sua matéria "Sustentabilidade na 
hotelaria" que a empresa Mapie ${ }^{1}$, em 2016, realizou uma pesquisa sobre o "Futuro da Hotelaria", a qual revelou que "75\% dos hóspedes da nova geração consideram a estrutura ambientalmente sustentável como um item que faz a diferença no hotel.” Assim, os resorts deixam claro o atendimento às questões ambientalmente sustentáveis, quando pontuam 100\% do atendimento aos itens obrigatórios presentes na Matriz de Classificação com suas práticas desenvolvidas nos resorts A, B e C, o que pôde ser confirmado pelas certificações ISO recebidas.

A partir das informações obtidas na pesquisa sobre os resorts A, B e C do complexo turístico do Porto das Dunas, bem como análise documental e aplicação em campo dos questionários, como base os requisitos do não mais em vigor o SBClass e as avaliações no TripAdvisor, tem-se um resultado considerável e importante, à medida que se constatou a confirmação da presença efetiva dos requisitos de infraestrutura, serviços e sustentabilidade nos respectivos empreendimentos.

\section{CONSIDERAÇÕES FINAIS}

O trabalho investiga os requisitos do não mais em vigor o Sistema Brasileiro de Classificação de Meios de Hospedagem (SBClass) nos empreendimentos hoteleiros do complexo turístico do Porto das Dunas, mais especificamente os que são auto classificados pelo complexo como resorts. Os requisitos em questão são: infraestrutura, serviços e sustentabilidade.

A relevância do tema estudado se dá pelo fato de que, há muitas décadas, os governos do Brasil buscam implantar um sistema de classificação de meios de hospedagem que seja eficiente e possua requisitos que atendam às necessidades dos empreendimentos hoteleiros, bem como dos hóspedes. Logo, o fato de estudar os requisitos presentes na Matriz de Classificação do último Sistema de Meios de Hospedagem implantado, em 2011 e finalizado em 2017, o SBClass, dentro de três resorts conceituados, por fazerem parte do Complexo Turístico do Porto das Dunas, torna-se uma oportunidade de verificar se os requisitos propostos na referida Matriz condizem com a realidade presente nos meios de hospedagem.

O resultado do estudo proporciona para o meio acadêmico, para a sociedade, e para os empreendimentos que são objetos de estudo, uma forma de se identificar quais os estabelecimentos hoteleiros no país possuem requisitos básicos para se auto classificarem na

\footnotetext{
1 Empresa que presta, desde 2009, consultoria especializada em hotelaria, gastronomia, turismo e serviços, buscando por soluções inteligentes, bem como, metodologias consistentes e criativas para que os clientes alcancem resultados efetivos na indústria da hospitalidade. (Mapie, 2018)
} 
categoria hoteleira de resort. Foi perceptível durante a análise dos dados nesse artigo que a não aderência e permanência de um sistema de classificação hoteleira oficial, neste caso, o SBClass que durou apenas 07 anos limita o desenvolvimento de novas pesquisas que abordem os critérios de classificação dos estabelecimento da rede hoteleira nesse país, bem como possíveis ações que garantem melhores nos quesitos infraestrutura, serviços, recursos humanos e sustentabilidade.

Somado a isso, percebeu-se que nos resorts pesquisados nenhum deles foi classificado pelo SBClass ou qualquer outro sistema oficial de classificação do MTur. E mesmo diante da verificação a partir da Matriz de Classificação proposta para a tipologia resort, os três resorts atendem, em todos os requisitos de infraestrutura, serviços e sustentabilidade, um percentual de, respectivamente: $86 \%, 83 \%$ e $100 \%$ dos itens propostos como obrigatórios presentes em suas instalações e serviços adotados, o que não os classificaria como resorts pelo MTur, tendo em vista que precisariam atendem a $100 \%$ dos itens obrigatórios.

Mas o índice atingido de forma considerável pelos resorts, mesmo que não sendo em sua totalidade, mostra que aquilo que está proposto na Matriz de Classificação condiz com a realidade do meio hoteleiro, tendo em vista que os resorts do complexo turístico do Porto das Dunas adotam como parâmetro de observação outros empreendimentos da mesma categoria, ou seja, outros resorts quatro estrelas, de outros estados do Brasil. O fato de terem outros empreendimentos como parâmetros, e não um Sistema de Classificação Oficial, implantado pelo Governo, reflete a forma desacreditada como vem sendo vistas as ações e políticas públicas do turismo, implantadas pelo MTur desde sua criação, em 2003.

Tal percepção foi constatada pela não adesão dos resorts estudados aos Sistemas de Classificação implantados, durante os 15 anos em que existe o MTur, e é confirmada, durante a pesquisa, com a informação de desativação do SBClass pelo ex-ministro do Turismo, Marx Beltrão, na minuta feita em 17 de fevereiro de 2017, de Projeto de Lei com propostas que alteram a Lei $\mathrm{n}^{\mathrm{o}} 11.771$, de 17 de setembro de 2008. A justificativa deu-se pelo fato de que só haviam sido classificados pelo SBClass 59 meios de hospedagem, do total de mais de 25 mil existentes no Brasil, o que constatou seu fracasso na adesão pelas empresas hoteleiras.

Evidencia-se a falta de adesão dos meios de hospedagem junto ao Sistema de Classificação proposto pelo MTur, pois durante 07 anos de existência de um Sistema de Classificação, ter-se um percentual médio de $2 \%$ de adesão do total é algo inexpressivo, que põe em questão e análise as ações do MTur junto aos segmentos onde atuam. Essa não adesão por parte dos empreendimentos, em todo o Brasil, ocorre possivelmente pela ausência de 
planejamento para o turismo no Brasil que seja duradouro, reflexo da presença instável de líderes que fiquem à frente do Ministério em questão.

Desde sua implantação até então, o MTur já apresentou 12 ministros em seu comando, ou seja, cada um possui pensamentos diferentes, que geram ações e projetos distintos, daí instaura-se a instabilidade e falta de crédito pelas empresas que teriam o MTur como referência ou suporte de orientação.

Aponta-se que os objetivos geral e específicos foram alcançados, o geral, que foi analisar os requisitos propostos para a classificação da tipologia resort no Sistema Brasileiro de Classificação de Meios de Hospedagem (SBClass) nos três empreendimentos hoteleiros, auto classificados de resorts, que compõem o complexo turístico do Porto das Dunas, à medida que se conseguiu analisar os requisitos propostos para a classificação do resort no (SBClass) nos três resorts citados, a partir da aplicação da Matriz de Classificação, em cada um dos empreendimentos, fazendo-se um paralelo da existência dos itens, por meio das avaliações dos clientes que se hospedaram nos três resorts.

Além disso, pode-se: a) verificar quais requisitos do SBClass, mandatórios e eletivos, são atendidos pelos empreendimentos hoteleiros do complexo turístico do Porto das Dunas, a partir da matriz de classificação do SBClass, verificação essa que foi feita a partir da referida matriz, realizando-se uma exposição desse resultado por meio de quadros com quantitativos expostos para cada um dos requisitos explanados; b) explanar sobre os requisitos de infraestrutura, serviços e sustentabilidade do SBClass, o que foi concretizado de maneira individual sobre cada requisito, a partir da fundamentação de vários autores, bem como de fontes infográficas com posicionamentos atuais sobre tais requisitos; e c) investigar a avaliação, por parte dos clientes, em relação aos serviços, infraestrutura e sustentabilidade nos meios de hospedagem estudados, o que foi possível diante das avaliações postadas na plataforma do TripAdvisor pelos clientes que se hospedaram nos três resorts, no período de março a maio de 2018.

Foi possível evidenciar que os questionamentos elencados foram respondidos. Os resorts do complexo turístico do Porto das Dunas atendem aos requisitos do Sistema Brasileiro de Classificação dos Meios de Hospedagem de forma insuficiente, pois, dos três requisitos que exigem o atendimento de $100 \%$ dos itens obrigatórios, os resorts só alcançaram essa totalidade no requisito de sustentabilidade, mas, para infraestrutura e serviços, o percentual alcançado foi de respectivamente: $86 \%$ e $83 \%$.

Quanto à aplicação e execução dos requisitos estudados, são percebidos pelos clientes que se hospedam nos resorts do complexo turístico do Porto das Dunas, os quais apontam em 
suas avaliações, conforme período dos dados coletados no TripAdvisor, pontos positivos para todos os requisitos, sendo destacados itens específicos nas avaliações, principalmente para infraestrutura e serviços; à medida que o requisito de sustentabilidade, os comentários, são relativos somente à praia. Há também atribuições negativas dos clientes em alguns, como destacado no item "preços", no que se refere ao setor de A\&B dos resorts.

Em face dos dados da pesquisa, percebe-se como necessário um posicionamento do MTur quanto ao uso das Matrizes de Classificação como documentos norteadores dos empreendimentos hoteleiros para adequação aos itens relativos aos requisitos de: infraestrutura, serviços e sustentabilidade, das tipologias para as quais já foram criadas as Matrizes. Para esse direcionamento, poderia ser verificada a possibilidade de uma parceria com as Secretarias de Turismo de cada estado, a fim de divulgar junto às empresas e tornar concreta a utilização das Matrizes nos empreendimentos, para ter-se um padrão das tipologias quanto aos parâmetros já existentes.

A partir dessa ação, o MTur necessita repensar na criação de um Sistema de Classificação Oficial do Governo que seja de adesão obrigatória, mas gratuita, a fim de teremse empresas hoteleiras com padrões definidos, as quais se cadastrem e recebam fiscalizações, para verificação do atendimento aos requisitos propostos pelo MTur em sua nova classificação, que pode usar como parâmetro as Matrizes de Classificação existentes e as novas matrizes que forem elaboradas para outras tipologias.

Quanto aos resorts do complexo turístico do Porto das Dunas, entende-se como relevante que os gestores possam observar quais itens encontram-se ausentes nos hotéis, de acordo com a Matriz do SBClass, e possam implantá-los. Pois mesmo que o SBClass tenha sido desativado, as matrizes que já haviam sido desenvolvidas para as sete tipologias das quais os resorts fazem parte tornaram-se um parâmetro de referência pelo MTur, para uso e adequação dos empreendimentos. Deveria ser uma preocupação do Complexo se adequar por completo a esses parâmetros do MTur, tendo em vista que ele é o Ministério que regulamenta a atuação dos empreendimentos do Brasil.

E para o Complexo, por ser uma referência para o turismo e a hotelaria, seria importante não apresentar fragilidades e insucessos frente a um Sistema Oficial de Classificação, e sim ser exemplo, aderindo e agregando valores, a partir de seu cumprimento na íntegra. Até porque os itens que faltaram ser atendidos nos hotéis para atingirem os $100 \%$ e serem enquadrados na tipologia resort foram poucos, correspondendo a $14 \%$ e $17 \%$ dos itens de infraestrutura e serviços que se mostraram ausentes. Uma ação de implantação desses itens, pela gestão, 
resolveria e adequaria os empreendimentos na tipologia resort, de acordo com todos os requisitos propostos pelo MTur na sua matriz oficial de classificação.

Frente aos dados levantados nesse estudo, sugere-se para pesquisas futuras investigar a importância e necessidade de um sistema de classificação para os meios de hospedagem no Brasil, os quais se encontram, após desativação e não sucesso do SBClass, sem nenhum sistema oficial de classificação ativo, apenas disponibilizados as matrizes que foram criadas e, hoje, podem ser usadas como material orientador.

Portanto a pesquisa confirma que os empreendimentos localizados no Complexo Turístico do Porto das Dunas atendem aos requisitos do não mais vigente SBClass e apesar de não existir uma classificação hoteleira oficial, manifesta-se o contentamento de terem sidos alcançados os objetivos propostos inicialmente, bem como terem-se obtido respostas aos questionamentos levantados. Registre-se, assim, a satisfação em poder contribuir com reflexões a respeito dos empreendimentos hoteleiros, em especial dos resorts, apresentados em número tão amplo no Brasil; e numa possível e futura existência de um novo Sistema Brasileiro de Classificação Hoteleira, no qual esses empreendimentos poderão se adequar e fazer parte, assunto que oportunizará estudos posteriores e uma longa e prazerosa caminhada de estudo.

\section{REFERÊNCIAS}

Associação Brasileira de Resorts. (2017). Resorts. Recuperado em 12, janeiro, 2018, de https://resortsbrasil.com.br/

Appelt, J. L., \& Lopes, L. A. M. (2006). Análise Comparativa da atuação dos profissionais do lazer em 02 Resorts: Sheraton Vistana Resort e Rio Quente Resort. Anais do IV Seminário de Pesquisa em Turismo do MERCOSUL - SeminTUR. Universidade de Caxias do Sul, Caxias do Sul, RS, Brasil.

Beni, M. C. (2002). Análise estrutural do turismo. São Paulo: SENAC.

Brasil. Ministério do Turismo. (2010). Cartilha de Orientação Básica - Resort. Recuperado em 08, janeiro, 2018, de http://www.classificacao.turismo.gov.br/MTUR-classificacao/mtursite/Entenda?tipo=2

Brasil. Ministério do Turismo. (2014). Classificação dos meios de hospedagem. Recuperado em 12, janeiro, 2018, de http://www.classificacao.turismo.gov.br/MTUR-classificacao/mtursite/index.jsp

Brasil. Ministério do Turismo. (2017). Cadastur: mais de 70\% dos meios de hospedagem do país estão irregulares. Recuperado em 23, abril, 2018, de http://www.turismo.gov.br/\%C3\%BAltimas-not\%C3\%ADcias/8181-cadastur-mais-de-70dos-meios-de-hospedagem-do-pa\%C3\%ADs-est\%C3\%A3o-irregulares.html 
Brasil. Ministério do Turismo. (2018). Classificação dos meios de hospedagem. Recuperado em 12, janeiro, 2018, de http://www.classificacao.turismo.gov.br/MTUR-classificacao/mtursite/pesquisarClassificados

Campos, L. C. A. M., \& Gonsalves, M. H. B. (2005). Introdução a Turismo e Hotelaria. Rio de Janeiro: Ed. SENAC Nacional.

Castelli, G. (2003). Administração hoteleira. (9a. ed.). Caxias do Sul: EDUCS.

Corrêa, E. A. (2002). O papel do animador sócio-cultural em hotéis de lazer. Anais do $14^{o}$ ENAREL. Santa Cruz do Sul, RS, Brasil.

Correia, R. R., Alperstedt, G. D., \& Feuerschutte, S. G. (2017). O Uso do método Netnográfico na Pós-Graduação em Administração no Brasil. Revista de Ciências da Administração, 19(47), 163-175.

Duarte, V. V. (2005). Administração de Sistemas Hoteleiros. São Paulo: SENAC.

Esteves, Y. de O. (2011). Marketing, internet e o comportamento do e-consumidor. Anais do VII Congresso Nacional de Excelência em Gestão. Rio de Janeiro, RJ, Brasil.

Lei $n$. 6.505, de 13 de dezembro de 1977. (1977). Dispõe sobre as atividades e serviços turísticos; estabelece condições para o seu funcionamento e fiscalização; altera a redação do artigo 18, do Decreto-lei $\mathrm{n}^{\circ}$ 1.439, de 30 de dezembro de1975; e dá outras providências. Brasília, DF. Recuperado de http://www.planalto.gov.br/ccivil_03/leis/1970-1979/16505.htm

Lei $n^{o}$ 8.181, de 28 de março de 1991. (1991). Dá nova denominação à Empresa Brasileira de Turismo (Embratur), e dá outras providências. Brasília, DF. Recuperado de http://www.planalto.gov.br/ccivil_03/leis/L8181.htm

Lei $n^{o} 11.771$, de 17 de setembro de 2008. (2008). Dispõe sobre a Política Nacional de Turismo, define as atribuições do Governo Federal no planejamento, desenvolvimento e estímulo ao setor turístico; revoga a Lei no 6.505, de 13 de dezembro de 1977, o Decreto-Lei no 2.294, de 21 de novembro de 1986, e dispositivos da Lei no 8.181, de 28 de março de 1991; e dá outras providências. Brasília, DF. Recuperado de http://www.planalto.gov.br/ccivil_03/_Ato2007-2010/2008/Lei/L11771.htm

Iso 14001. (2018). Recuperado em 08, abril, de https://certificacaoiso.com.br/iso-14001/

Kozinets, R.V. (2010). Netnografia: a arma secreta dos profissionais de marketing. Como o conhecimento das mídias sociais gera inovação.

Marconi, M. A., \& Lakatos, E. M. (2016). Fundamentos de metodologia científica. (7a. ed.). São Paulo: Atlas.

Mapie. (2018). Mapie consultoria. Recuperado em 14, maio, 2018, de http://www.mapie.com.br/\#/sobre

Mota, K. C. N., Vianna, S. L. G., \& Anjos, F. A. (2013). Competitividade das destinações turísticas. Estudos de casos brasileiros. São Paulo: Atlas.

Revista Hotéis. (2016). Sustentabilidade na hotelaria. Recuperado em 14, maio, 2018, de http://www.revistahoteis.com.br/sustentabilidade-na-hotelaria/

Santos, G. E. O., \& Kadota, D. K. (2012). Economia do Turismo. São Paulo: Aleph. 
Schluler, R. G. (2003). Metodologia da pesquisa em turismo e hotelaria. São Paulo: Aleph.

Serviço Brasileiro de Apoio às Micro e Pequenas Empresas - Sebrae. (2015). Relatório de inteligência. Série: Canais digitais - TripAdvisor.

Severino, A. J. (2007). Metodologia do Trabalho Científico. (23a. ed.). São Paulo: Cortez.

Tripadvisor. (2018). Avaliações. Recuperado em 02, maio, 2018, de

https://www.tripadvisor.com.br/Attraction_Review-g303285-d2342777-Reviews-

Porto_das_Dunas_Beach-Aquiraz_State_of_Ceara.html

Vieira, E. V. (2004). Qualidade em serviços hoteleiros: a satisfação do cliente é função de todos. Caxias do Sul, RS: Educs.

\section{FORMATO PARA CITAÇÃO DESTE ARTIGO}

AGUIAR, F. L. S., BRITO, A. S., \& PERINOTTO, A. R. C. (2020). Uma análise do antigo Sistema Brasileiro de Classificação de Meios de Hospedagem a partir do Complexo Turístico do Porto das Dunas, Fortaleza/Brasil. Revista de Turismo Contemporâneo, 8(2), 168-197. https://doi.org/10.21680/2357-8211.2020v8n2ID19603 